\title{
A consciência: algumas concepções atuais sobre sua natureza, função e base neuroanatômica
}

\author{
Maurício Marx e Silva* \\ Alida Vitória Álvares Fuhrmeister** \\ Antônio Francisco Maineri Brum*** \\ Flávia Costa**** \\ Geraldo Rosito***** \\ Leandro Timm Pizutti \\ Madeleine Scop Medeiros $* * * * * *$ \\ Paulo Picarelli Ferreira ${ }^{\star \star \star \star \star \star * \star *}$

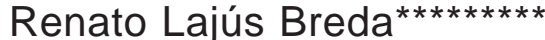

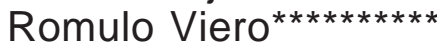

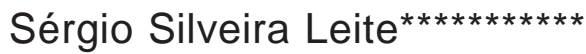

"A consciência é um fenômeno fascinante, porém elusivo;

é impossível especificar o que é, o que faz ou por que evoluiu.

Nada digno de ser lido foi escrito sobre ela."

Stuart Sutherland $(1989)^{1}$

"Se você estivesse projetando uma máquina orgânica para bombear sangue,

\footnotetext{
* Psiquiatra, Egresso SPPA, prof. Institutos Abuchaim e Contemporâneo.

** Psiquiatra, Graduada SPPA, prof.a Instituto Contemporâneo.

*** Psiquiatra, prof. FFFCMPA, Inst.Abuchaim e ULBRA.

${ }^{* * * *}$ Psiquiatra, Egressa SPPA, prof.a conv. UFRGS.

${ }^{* * \star * *}$ Psiquiatra, membro assoc. SBP de PA, prof Instituto Abuchaim.

${ }^{* * * * * *}$ Psiquiatra, membro prov. CEP de PA, prof IFP.

${ }^{* * * * * * *}$ Psiquiatra, supervisora da residência do HMIPV.

******** Psiquiatra, egresso da SBP de PA, prof. Instituto Abuchaim.

${ }^{* * * * * * * * *}$ Psiquiatra, Egresso da SBP de PA, prof Instituto Abuchaim e FUMM.

${ }^{* * * * * * * * * *}$ Médico, psicanalista, membro efetivo CEP de PA, prof. Instituto Contemporâneo.

${ }^{* * * * * * * * * *}$ Médico Psicoterapeuta, egresso Instituto Cyro Martins.
}

é bem provável que surgisse algo semeIhante a um coração. Mas se você estivesse inventando uma máquina para produzir consciência, quem pensaria em algo como uma centena de bilhões de neurônios?" John R. Searle(1997) ${ }^{2}$

"Se ninguém mo perguntar eu sei. Se o quiser explicar a quem me pergunte, já não sei!" Paráfrase de Santo Agostinho3:

"Estar consciente vai além de estar acordado e atento: requer uma sensação interna de um self no ato de conhecer". António Damásio (1999) ${ }^{4}$

\section{INTRODUÇÃO}

A partir principalmente de Freud, as atenções dos estudiosos da mente voltaram-se para o inconsciente, território tão misterioso na época que necessitava primeiramente ter comprovada sua existência para após reivindicar a condição de objeto de pesquisa. Mesmo nos primórdios da descoberta do inconsciente, entretanto, Freud já se questionava sobre a natu- 
reza da consciência. A questão aqui era, porém, muito diferente. $O$ fenômeno da consciência era tomado como evidente por qualquer indivíduo, devido a sua própria natureza de autopercepção. Não havia necessidade de provar sua existência. Talvez por isto, por este caráter de algo que "todos sabemos como é", é que tenhamos demorado tanto a lhe dedicar maior atenção (sistemática, pois o tema sempre persistiu como objeto de conjecturas filosóficas). Com o passar das décadas, o inconsciente tornou-se aceito como a regra dos processos mentais, não se constituindo em uma qualidade especial destes, e verificou-se que o mistério na verdade residia na sensação de estar consciente desses processos.

A primeira constatação a ser feita ao pensarmos na questão da consciência é a de que, apesar de "todos sabermos como é", na verdade não sabemos "o que é" a consciência, e nem mesmo podemos afirmar se o "como" de um é igual ao "como" de outro.

Nos últimos anos, alguns neurocientistas têm acrescentado insights esclarecedores sobre a questão da consciência. A primeira evidência neurobiológica interessante vem apoiar a distinção que existe na língua inglesa entre wakefulness (estar consciente no sentido de vigília, em oposição ao coma, como em "bater a cabeça e perder a consciência"), conscience (consciência moral, superegóica, como em "ter um peso na consciência") e consciousness (consciência no sentido da sensação de existir e de estar experienciando um dado momento, que inclui a sensação da passagem do tempo). Infelizmente, na língua portuguesa, os três conceitos podem ser expressos pela palavra consciência, o que contribui para uma indistinção. Embora a consciência nos dois últimos sentidos necessite de um grau mínimo de vigília, este grau mínimo já está dado na fase de sono R.E.M., quando se sonha, e na qual tanto podese ter a sensação de existir e de algo nos acontecer, de experienciar, quanto se pode perceber a influência da consciência moral. Constatou-se também que um estado pleno de vigília pode coexistir com uma abolição da consciousness, como em pacientes que sofrem de alguns tipos de crises convulsivas, nas quais são capazes de caminhar longos trajetos, executar funções relativamente complexas, sem a sensação de existir, de estar experienciando o que está acontecendo e sem a percepção da passagem do tempo, apesar de estarem "bem acordados".

A "sensação do que acontece" (The Feeling of What Happens), como Antônio Damásio entitulou em inglês seu último livro (em português "O Mistério da Consciência") pode persistir em pessoas que têm a perda de grandes partes do encéfalo, transitória ou definitiva, a ponto de não saberem sequer seus próprios nomes. Elas perdem os registros de sua história, mas não a sensação de serem alguém, um self, que está experienciando aquele momento. É a diferença entre a "consciência central" e a "consciência ampliada", esta última incluindo, além do self corporal, o "self autobiográfico"4.

Edmund Rolls, em "The Brain and Emotion" (1999), salienta o grande valor adaptativo da consciência que Damásio chama de ampliada, dos "pensamentos de segunda ordem", ou seja, o "pensar sobre o próprio pensar", que permite uma revisão (e às vezes correção) dos próprios processos de pensamento, ampliando enormemente as possibilidades de estratégia de ação e sofisticando a tomada de decisão ${ }^{5}$.

A "sensação do que acontece", presente durante o sonhar e ausente em certos estados de vigília como nas crises de ausência, é a propriedade de certos processos mentais que progressivamente têm se tornado alvo de estudo. Evidências recentes sugerem que tanto a sensação de continuidade da consciência quanto a impressão de que ela preceda a tomada de decisão seriam ilusórias. Também a antiga crença de que a consciência fosse uma função dependente de um funcionamento cortical global tem sido questionada. A evolução da consciência, a partir dos mecanismos de homeostase, como um feed-back sofisticado do estado corporal, incluindo os processos mentais, que permite a detecção de erros nas predições realizadas pelo cérebro sobre o self e o ambiente, com a possibilidade de correções em partes do processo mental sem a necessidade de descartá-lo por inteiro, é um exemplo das modernas compreensões sobre este tema e que tem importantes correlações com a clínica psicoterápica.

\section{HISTÓRICO EVOLUCIONISTA}

Há uma opinião válida segundo a qual o Homem é contemporâneo de todas as demais espécies sobreviventes de seres vivos e, na verdade, da própria vida, pois, embora a evolução se tenha processado por diferenciação, as diferentes espécies por ela produzidas são todas relacionadas entre si, como os ramos de uma árvore. Todos derivam de uma raiz comum. Se procurarmos determinar com mais precisão a gênese do Homem, escolheremos a data em que a família dos hominídeos se sepa- 
rou de outras famílias de primatas, marcando um ponto de ruptura geneticamente irreversível. Se considerarmos o homem tão antigo quanto a data em que deixou de ser possível a nossos ancestrais tornar-se qualquer coisa que não humanos, então deve-se considerar que o Homem teve sua origem, como forma distintiva de vida, há cerca de dois a dois e meio milhões de anos ${ }^{6}$.

Seria possível datar a idade da humanidade com precisão ainda maior, identificando-a a partir de algum traço anatômico distintivo, ou de hábitos e realizações distintivas, tais como o bipedismo, a encefalização crescente, o abandono da copa das árvores? Poderíamos datar a gênese da natureza humana pela realização de feitos como a sociabilidade e o desenvolvimento da linguagem, entendida como um código de sons transmitindo significados inteligíveis a todos os membros de uma comunidade, em oposição a um conjunto de exclamações expressando emoções?

Uma possibilidade para datar o acontecimento da aparição da natureza humana na biosfera não seria o desenvolvimento de uma característica anatômica, nem a aquisição de uma habilidade, mas sim o despertar da consciên$\mathrm{cia}^{7}$. Mas, o que é consciência? Ou seriam "as consciências"? E então qual delas? Mais especificamente, a Consciência Ampliada de Damásio? E qual seria a sua função? Como tal fenômeno surgiu no cérebro humano: terá ele surgido súbita e inteiramente formado no cérebro do Homo sapiens, sem nenhum tipo de precursor na natureza? Quando, na pré-história humana, a consciência atingiu o estágio que agora experimentamos? Que vantagens evolutivas teria ela conferido aos nossos ancestrais? Há sempre a possibilidade, é claro, de que ela não "sirva" para nada e seja simplesmente um subproduto de cérebros grandes em ação, como sugere o questionamento de Dennett: "Haverá qualquer coisa que uma entidade consciente pode fazer por si mesma que uma simulação inconsciente (mas habilmente programada) desta entidade não possa fazê-lo?"8. Entretanto, parece razoável adotar o ponto de vista evolutivo, que sustenta que um fenômeno mental tão poderoso provavelmente conferiu benefícios para a sobrevivência e foi, portanto, produto da seleção natural. Se nenhum de tais benefícios pode ser discernido, então talvez a alternativa "nenhuma função adaptativa" possa ser considerada ${ }^{3}$.

Tentar datar o despertar da consciência é muito difícil, senão audacioso, se supusermos que o mesmo foi um processo gradual que, embora talvez rápido em termos da escala geológica de tempo, pode ter levado uma eternidade em termos da escala de tempo da história humana registrada (aproximadamente 5.000 anos). Certamente a única espécie sobrevivente do genus homo não é a única variedade de hominídeos a possuir consciência. Acredita-se que o Homem de Neanderthal possuísse cerimônias fúnebres, ao invés de tratar os cadáveres de seus mortos como lixo. Ele parece ter sobrevivido até época tão recente quanto a transição da Idade Paleolítica Inferior para a Superior, talvez há uns setenta ou quarenta mil anos. Há até indícios de que havia comunidades mistas de Neandertalenses e Sapientes e, se isso existiu realmente, parece provável que esses dois tipos de seres humanos tenham sido fisicamente semelhantes o bastante para poderem acasalar-se. Todavia, o Homem de Pequim (Homo erectus da China), cuja data é estimada em cerca de meio milhão de anos, tem de ser considerado como uma espécie diferente; e, se é verdade que o Homem de Pequim já havia dominado o fogo, sua consciência deve ter sido bem desenvolvida. Também deve ter sido necessária uma centelha de consciência para pensar em lascar pedras, em lugar de usar apenas, como ferramentas, objetos naturais não modificados. A confecção de ferramentas com pedras lascadas é atribuída ao australopithecus, cuja data é estimada em cerca de dois a três miIhões de anos, classificado como hominídeo, mas não como homo. E tampouco há certeza quanto ao fato de ele ser ou não ancestral do homo. Registros não-intencionais, sob a forma de ferramentas modeladas, são tão antigos quanto o australopithecus; mas os registros mais antigos, feitos com a intenção de servir como tais, têm apenas cerca de 20.000 ou 30.000 anos de idade, caso as pinturas nas paredes das cavernas na França e na Espanha, datando da Idade Paleolítica Superior, sejam os mais antigos registros intencionais de todos os tempos.

A evidência arqueológica pré-documentária informa acerca da tecnologia, mas a tecnologia é apenas uma condição que possibilita inferir os constituintes não-materiais do modo de vida do Homem: seus sentimentos e pensamentos, suas instituições idéias e ideais. Essas são manifestações da natureza humana mais importantes do que a tecnologia; uma das características mais distintivas do Homem é o fato de que ele não vive apenas de pão, e embora os restos materiais da tecnologia realmente lancem luz sobre algumas das facetas não-materiais da vida humana, essa luz é pouca. Inferên- 
cias do que é material para o que é mental são, em algum grau, tiros no escuro, e, quando a evidência material é tudo o que temos, deixa alguns aspectos da vida mental envoltos em ainda muita obscuridade. Dessa forma, nossas informações são muito mais copiosas e esclarecedoras em relação aos últimos 5.000 anos de história do que em relação ao primeiro miIhão ou meio milhão de anos depois do despertar da consciência. Contudo, um fenômeno provavelmente fundamental na evolução do cérebro, que permitiu a consciência ampliada como a reconhecemos em nós mesmos, é relativamente conhecido: a neotenia.

\section{A NEOTENIA}

Blanc ${ }^{10}$, escreve:

"S.J.Gould lembrou corretamente, em 1977, em um importante livro, Ontogeny and Phylogeny, que o homem difere do chimpanzé por um forte retardamento em seu desenvolvimento. Com efeito, é preciso saber que o homem e o chimpanzé passam pelas mesmas etapas durante o desenvolvimento pós-natal, e um feto de chimpanzé lembra bastante um feto humano. Após o nascimento, o bebê chimpanzé evoca ainda fortemente o bebê humano. Porém, conseqüentemente, as diferenças morfológicas tornam-se importantes, e um chimpanzé adulto lembra apenas remotamente um ser humano... Os biólogos empregam o termo neotenia para designar este fenômeno de fetalização, ou mais exatamente de juvenilização. Outros exemplos de neotenia são conhecidos no reino animal... no homem ela fixou-se definitivamente no patrimônio genético da espécie... De fato, é provável que o surgimento do homo habilis...tivesse correspondido a uma mutação dos genes de regulação do desenvolvimento, que teve como efeito retardar consideravelmente a totalidade do desenvolvimento pré e pós-natal. Podemos comparar sua importância comparando o homem atual e o chimpanzé. A ossificação no recém-nascido humano está muito atrasada em relação à observada no bebê chimpanzé(os dedos e as extremidades dos ossos são ainda cartilaginosos no nascimento). O bebê humano começa a andar por volta dos 10-12 meses, enquanto que o bebê chimpanzé começa a mover-se por si mesmo em torno dos 6 . O pequeno humano ganha seus primeiros dentes apenas entre 6 e 24 meses, contra 3 e 13 meses no chimpanzé. A idade da puberdade é atingida aos 13 anos na espécie humana, contra 9 no chimpanzé. O período de crescimento não pára antes dos 20 anos no homem, contra 11 no chimpanzé. (Este último tem uma estimativa de vida mais ou menos de 45 anos, contra 75 anos para o homem atual.) Uma outra diferença capital entre o desenvolvimento do homem atual e o do chimpanzé diz respeito à velocidade de crescimento do cérebro: no recém-nascido humano, o cérebro representa apenas 23\% do peso que atingirá na idade adulta, contra $40 \%$ no recém-nascido chimpanzé. Em outros termos, o cérebro continua a crescer após o nascimento, em proporções bem mais consideráveis no homem que no chimpanzé. De onde um volume cerebral médio na idade adulta de $1350 \mathrm{~cm} 3$ no primeiro, contra $400 \mathrm{~cm} 3$ no segundo... O ser humano apresenta em sua morfologia toda uma série de caracteres, ditos neotênicos, próprios dos estágios precoces do desenvolvimento do chimpanzé: o pêlo não é uma característica do feto do chimpanzé(este adquire sua pelagem apenas nos últimos momentos da gestação); a orientação do grande artelho paralelo aos outros dedos do pé é um estágio fetal precoce de todos os primatas(no final do desenvolvimento pré-natal, o polegar do pé ou da mão sofreu, em todos os macacos, uma rotação, para tornar-se oposicionável aos dedos e permitir preensão); a ausência de proeminências ósseas acima das órbitas, a frágil espessura dos ossos são também caracteres de fetos de macaco, etc. Podemos, assim, chegar a fazer uma lista que compreende duas dezenas de caracteres neotênicos no homem ${ }^{10}$.

Dentre as muitas listagens feitas por diversos autores, citadas por Gould ${ }^{11}$, destaca-se a de Montagu, que salienta o prolongado período de dependência infantil como um destes caracteres neotênicos. As imagens seguintes são também ilustrativas: 


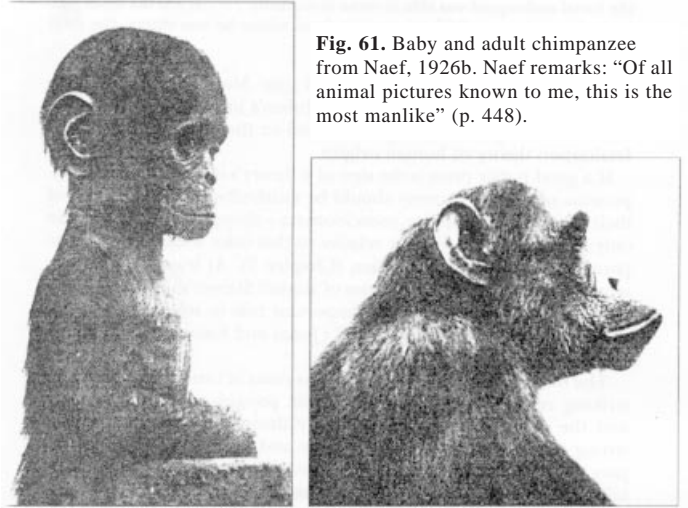

As repercussões da neotenia sobre a condição humana são mais especificadas por Gould e outros autores citados por ele:

"Este retardamento reagiu sinergisticamente com outros marcos da hominização com a inteligência (através de aumentar o cérebro pelo prolongamento de tendências de crescimento fetais e por prover um período mais longo de aprendizado infantil) e com a socialização (através de cimentar as unidades familiares pelo cuidado parental aumentado da prole de maturação lenta)...O prêmio adaptativo assim colocado no aprendizado (em oposição à resposta inata) é único entre os organismos... O homem é programado para aprender comportamentos, mais do que reagir via um código instintual determinante impresso... A correlação da maturação com a perda de plasticidade (mental tanto quanto física) foi há muito reconhecida... Konrad Lorenz em particular tem repetidamente enfatizado o caráter persistentemente 'juvenil' de nossa flexibilidade comportamental... a 'neotenia comportamental' é apenas uma outra conseqüência do retardamento desenvolvimental que permitiu nossa neotenia morfológica: 'o caráter constitutivo do homem -a manutenção de uma interação ativa, criativa, com o ambiente - é um fenômeno neotênico... ampliado para persistir até a senilidade'”11.

Ou seja, a prematuridade, este fato básico da natureza humana, não ocorre somente no início da vida como se acreditava quando se pensava que o fator biológico fosse um nascimento precoce fruto da aquisição da bipedestração, mas é persistente por toda a vida do indivíduo até a senilidade. Poderíamos preferir pensar que a percepção do estado de desam- paro decorrente da imaturidade pertence somente ao início da vida, mas aí estaríamos em dificuldades para entender a difusão de muitas produções da civilização, especialmente o apelo das teorias místicas, religiões, terapias de vidas passadas por exemplo, que visam a negar a maior impotência de todas que é a que sentimos diante da consciência da morte.

\section{HIPÓTESES ATUAIS SOBRE A NATUREZA DA CONSCIÊNCIA}

Em nossa opinião, as proposições de Antônio Damásio, embora não totalmente originais, representam um marco na compreensão da questão da consciência. Tanto pela clareza de suas proposições, quanto pelo raciocínio desenvolvido a partir de evidências obtidas de pacientes com alterações cerebrais específicas em correlação com as alterações observadas ou não nestes mesmos pacientes, fornecendo uma base mais firme para a construção de hipóteses, a compreensão do fenômeno da consciência certamente deverá muito a ele.

Apresentaremos aqui um esboço básico de algumas de suas hipóteses, já intercalando-as com alguns acréscimos de outros autores:

Damásio propõe uma distinção fundamental entre consciência central e consciência ampliada. A consciência central corresponderia, como mencionado acima, na sensação de ser alguém, um self, que existe e está vivenciando o momento atual. Esta consciência central prescindiria do que entendemos como o mais sofisticado de nosso cérebro, da maior parte da córtex (na verdade quase toda a neocórtex pode estar gravemente lesada e um paciente manter a consciência central, mesmo que não saiba o próprio nome). Esta consciência central necessitaria basicamente de estruturas localizadas no tronco cerebral e do giro do cíngulo, áreas bastante antigas e primitivas do ponto de vista filogenético e presentes na maioria dos mamíferos, o que o leva a supor que estes animais possuam algo semelhante a esta "sensação de existir".

As estruturas neuroanatômicas necessárias à consciência central são estrururas relacionadas aos mecanismos homeostáticos básicos, levando Damásio a cogitar que a natureza essencial da consciência seja a de um mecanismo homeostático, auto-regulador, de feedback. Ele propõe que para esta consciência central sejam necessários três mapas neurais. Um mapa é um grupo de neurônios que guarda uma correlação constante com um tipo de estímulo, seja uma região do corpo, um tipo especí- 
fico de percepção nesta região (por exemplo, a sensação proprioceptiva do interior da articulação do joelho) . O primeiro mapa seria o mapa do self corporal, que ele chama de protoself. $O$ segundo seria o chamado mapa do objeto, daquilo reconhecido como não-self. O terceiro mapa seria um mapa destinado a registrar as mudanças no protoself ocasionadas pela relação com os objetos, com o ambiente, em tempo real (escaneamento total realizado a cada aproximados 13 milissegundos, como veremos adiante).

Neste ponto da teorização de Damásio, cremos importante intercalá-la com a do neurocientista Llinas, que, baseado em uma boa gama de evidências de registros cerebrais correlacionados com tomadas de decisões e ações, propõe, e é respaldado por diversos colegas ilustres, que o cérebro funcione como um "sistema fechado". Llinas ${ }^{12}$ argumenta que o cérebro tem um funcionamento eminentemente antecipatório, autoativado, relativamente independente do ambiente, trabalhando mais e antes com as expectativas que gera sobre o ambiente a partir dos registros mnêmicos prévios do que com as percepções imediatas. Essas percepções teriam um caráter mais corretivo do que causal com relação ao comportamento. Isto se daria em função da velocidade muito maior que este funcionamento antecipatório permitiria. Quando os inputs perceptuais divergem da antecipação, o que sempre ocorre em alguma medida, este fato desperta os mecanismos atencionais, a divergência "chama a atenção", e desperta a consciência, que seria um mecanismo bastante mais lento que o processamento cerebral usual e posterior a este. A consciência faria uma revisão secundária, embora imediata, do processo mental utilizado na produção das antecipações, para verificar qual o erro ou afinamento necessário para gerar antecipações mais perfeitas. Llinas e outros chegam a descrever o estado de consciência na vigília como um "sonho modificado pelos inputs sensoriais e pelos outputs motores"12. Embora tenhamos a impressão de que a consciência é o que precede a tomada de decisão, ela na verdade seria um produto de decisões já tomadas e implantadas inconscientemente pelo cérebro. Esta concepção se aproxima muito da ênfase da psicanálise das últimas décadas no mundo interno como essencial para a compreensão do comportamento humano.

Muitos autores têm ressaltado que várias descobertas recentes com relação à consciência são contra-intuitivas, diferentes da impressão que tendemos a ter usualmente. Uma delas é a tendência que temos a sempre pensar que a consciência é "outra coisa" além dos processos neurais que estamos descrevendo, que estes processos "causam" a consciência, e não "são" a consciência ${ }^{13}$. Churchland assinala este erro no pensamento do importante neurofilósofo John Searle, comparando com concepções leigas como a de que o movimento dos elétrons num condutor "causa" a eletricidade e não que este movimento "é" a própria eletricidade. Esta forma de pensar retoma disfarçadamente o dualismo mente-corpo cartesiano ${ }^{14}$.

Voltando às antecipações geradas pelo cérebro constantemente, a antecipação fundamental para a consciência central seria a da continuidade inalterada do protoself corporal, ou seja, da homeostase, e as alterações ocasionadas no protoself corporal pela relação com o ambiente necessitariam receber atenção para despertar o mecanismo de revisão secundária da consciência, que buscaria em última análise retomar a homeostase ou impedir um maior desequilíbrio.

Obviamente que a consciência ampliada, aquela que incluiria tudo o que Damásio chama de self autobiográfico, portanto com toda a sofisticação que estamos acostumados a reconhecer, pode projetar ações de manutenção da homeostase a longo prazo, que incluam no curto prazo até mesmo um desequilíbrio maior desta mesma homeostase, o que Freud chamaria de uma vitória do princípio de realidade sobre o princípio do prazer.

Neurocientistas como Olds e Deacon ${ }^{12}$ argumentam que, neste modelo, a consciência auto-reflexiva re-representa simbolicamente os dados obtidos via percepções, assim tornandoos independentes de sua fonte. Assim se cria uma "cena virtual" (vide também adiante "o problema do enlace"). A comparação é feita com uma videocâmera. Se não há memória(ou fita) na câmera, só temos uma imagem fugidia. Se há memória, seja fita ou digital, então a cena pode ser recuperada independente do ambiente que a gerou, ser manipulada, editada. Se por um lado isto aumenta imensamente o que se pode fazer com estes dados, também abre o caminho para as distorções, as defesas, as reconstruções. Solms lembra que Freud propunha, em 1917, que

"a psicanálise propõe que a atividade mental é inconsciente em si mesma. Isso implica que a consciência não é somente uma parte da atividades mental: ao invés disso, ela é um reflexo da atividade mental ou uma percepção da atividade mental que é, 
ela mesma, inconsciente. Assim, a atividade mental não consiste numa corrente causal em que alguns de seus elos são conscientes e outros não. A proposta é que a atividade mental consiste numa corrente causal que é inconsciente em sua essência e que a consciência representa este processo de forma 'incompleta e não-confiável' ". ${ }^{15}$

Edmund Rolls ${ }^{5}$, neurocientista de Oxford, propõe que esta revisão secundária, a que ele chama de "pensamentos de segunda ordem", já no domínio da consciência ampliada, teria a vantagem de permitir uma correção de partes do processo mental, libertando-o da "tentativa e erro", na qual se o resultado final de alguma estratégia comportamental é indesejável estamos condenados a descartá-lo integralmente e tentar outro, algo como "jogar fora o bebê junto com a água do banho". Neste processo sofisticado da consciência ampliada, a linguagem joga um papel fundamental, potencializando enormemente a capacidade de revisão e a sofisticação das antecipações. Linguagem aqui é entendida como a capacidade de articulação de imagens e símbolos, não necessariamente verbais. Neste enfoque a linguagem tem uma participação importante na consciência ampliada, mas não é essencial para a consciência central.

\section{O PROBLEMA DA INTEGRAÇÃO OU DO ENLACE}

Durante um passeio ao ar livre, nossos sentidos vão sendo ocupados por variados estímulos: nosso campo visual é preenchido por carros, árvores, casas, outras pessoas, animais - cada um com sua forma específica, sua cor específica e específica posição no campo visual. Alguns objetos podem estar em movimento, emitir sons ou cheiros. Além disso, esses objetos podem estar relacionados a outros por específicas e significativas vias, e nós podemos atribuir um conceito e um nome a cada um deles, sendo que o número de objetos e situações que podemos perceber é praticamente infinito. Obviamente não pode haver um tipo de neurônio que corresponda a cada objeto, pois necessitaríamos de um cérebro gigantesco. Tampouco pode haver mapas compostos de redes de neurônios que funcionem com o fim de reconhecer cada objeto ou situação, pois isso exigiria um cérebro de dimensão enciclopédica. $\mathrm{Na}$ verdade, há um número enorme, porém finito, de neurônios que avaliam as características de cada objeto. Cada conjunto de neurônios especializado em analisar atributos distintos de cada objeto - no caso das imagens visuais sabemos que há analisadores para forma, cor, movimento, contraste e profundidade entre outros - encontra-se localizado em áreas distintas do cérebro, razão pela qual deve haver um mecanismo que enlace temporalmente a atividade de todos eles, de maneira que a percepção possa ser experimentada como uma unidade perceptual unificada. Contudo, em que pese toda esta extraordinária riqueza e diversidade, aquilo que estamos vivenciando em um momento qualquer é uma singular cena consciente unificada, uma cena que é significativa apenas como um todo e que, enquanto está sendo vivenciada, não pode ser dividida em seus componentes independentes. Momento a momento, a cena, todavia, muda continuamente enquanto acontece o passeio.

Parece que o "truque" que o cérebro utiliza para compor uma cena singular, coerente e unificada a partir da fragmentação intracerebral da realidade externa é o disparo simultâneo, correlacionado em um instante, de todos os neurônios implicados na análise dos atributos de cada objeto particular. Portanto, ver um objeto implica a ativação de vários neurônios em diferentes localizações do sistema visual de maneira correlacionada. O problema do enlace, do ponto de vista neurobiológico, é entender como esses neurônios se ativam temporalmente de maneira síncrona, particularmente quando mais de um objeto ou evento pode ser percebido simultaneamente. Ou então, como questiona Gerald Edelman ${ }^{16}$ : "Como um conjunto de diversos mapas funcionalmente separados, podem estar ligados sem um mecanismo controlador de ordem superior?"

Uma abordagem possível para solucionar o problema, no caso da visão, foi proposta por vários pesquisadores, principalmente por Wolf Singer e seus colegas ${ }^{17}$, em Frankfurt, mediante experimentos realizados em gatos. Estes cientistas registraram oscilações periódicas no córtex visual, que tem uma freqüência média ao redor de 40 ciclos por segundo, isto é, $40 \mathrm{~Hz}$. Lembremos que os disparos de cada neurônio, quando se apresenta um objeto no campo visual, são potenciais de ação ou impulsos nervosos "tudo ou nada". Estes disparos são registrados com microeletrodos extracelulares muito finos, que têm uma extremidade de poucas micra. A soma dos campos elétricos produzidos por cada potencial de ação origina um potencial macroscópico que pode ser registrado com um eletrodo maior nas vizinhanças dos neurônios que disparam, gerando um potencial de campo 
local que oscila a $40 \mathrm{~Hz}$ e representa a atividade média dos neurônios que disparam na vizinhança do eletrodo. Se são utilizados dois eletrodos separados um do outro por uma distância de alguns milímetros, Singer e colaboradores constataram que os disparos registrados por cada um dos eletrodos estão correlacionados e em fase com a oscilação de $40 \mathrm{~Hz}$, o que significa que os neurônios que se encontram localizados em distintas áreas do córtex visual respondem ao objeto percebido disparando potenciais de ação simultaneamente. Para estes neurocientistas, as oscilações de $40 \mathrm{~Hz}$ no córtex visual são a base neural do enlace no tempo, por meio de um mecanismo que sincroniza o disparo de uns neurônios com outros. Francis Crick e seu colega Christof Koch levam esta hipótese um passo à frente e sugerem que, talvez, descargas neuronais nesta amplitude (em torno de $40 \mathrm{~Hz}$, mas não tão baixo quanto 35 ou tão alta quanto 75 ) possam ser o "correlato cerebral" da consciência visual'.

A hipótese é coerente e suscetível de ser provada, mesmo que circunscrita ao sistema visual, embora deixe pendente o problema de como e quem sincroniza o disparo dos neurônios implicados na percepção de um objeto, os quais se encontram localizados em distintas áreas cerebrais. Uma possível resposta vem de outra hipótese que engloba as anteriores e de algumas observações que começam a sustentá-la: R. Llinás e seu grupo consideram que o cérebro é um sistema fechado capaz de gerar seus próprios ritmos baseado nas propriedades elétricas intrínsecas dos neurônios que o compõem, assim como de suas conexões ${ }^{18}$.

A primeira observação relevante neste contexto é que os neurônios em qualquer parte do córtex cerebral são capazes de oscilar a $40 \mathrm{~Hz}$, devido as suas propriedades elétricas intrínsecas. A segunda observação crucial foi realizada por meio da técnica de Magnetoencefalografia (MEG), que permite registrar os pequenos campos magnéticos que são produzidos pelas correntes dos neurônios ativados em diferentes áreas do cérebro, através de 37 sensores magnéticos dispostos ao redor da cabeça de um indivíduo. Com esta técnica, tem-se observado que, durante a execução de atos cognitivos, durante a estimulação sensorial ou durante o sonhar, apresenta-se uma atividade oscilatória coerente em todas as áreas do córtex cerebral, com uma freqüência de $40 \mathrm{~Hz}$, o que sugere a existência de uma causa comum, um sistema sincronizador cortical. Uma vez que todo o córtex cerebral conecta-se com o tálamo de maneira recíproca, tem sido postulado que as osci- lações podem sincronizar-se por interações sinápticas recíprocas entre os núcleos intralaminares do tálamo e as diferentes áreas do córtex. De fato, os neurônios talâmicos também mostram as oscilações de $40 \mathrm{~Hz}$, e os núcleos intralaminares formam anatomicamente uma espécie de meia lua que recebe e emite conexões de e para todo o córtex cerebral, formando uma espécie de leque fronto-caudal.

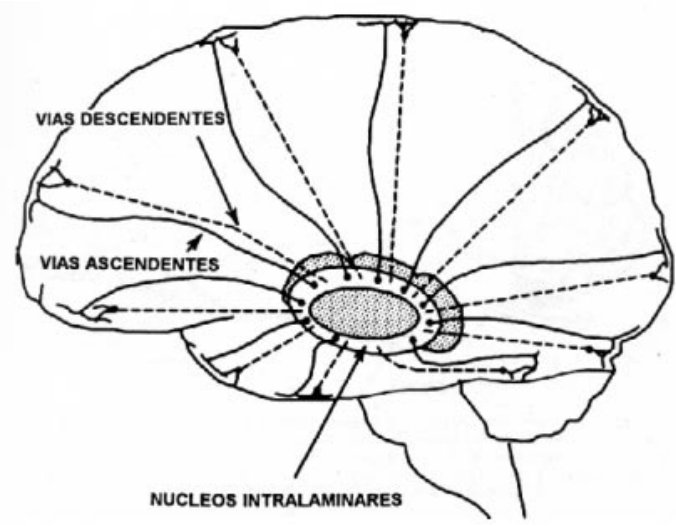

Esquema que representa o leque de conexões recíprocas entre os núcleos intralaminares do tálamo e distintas áreas do córtex cerebral. As vias corticotalâmicas se representam com linhas interrompidas.

Ainda mais interessante é o que revelam os estudos com MEG, mostrando que a oscilação de $40 \mathrm{~Hz}$ é gerada nas regiões corticais frontais e logo nas caudais, isto é, as oscilações se defasam rostrocaudalmente, de tal maneira que o cérebro se comporta como se tivesse um sistema de escaneamento que recorre todo o córtex cerebral em direção rostro-caudal, enlaçando toda a informação sensorial em intervalos de 12,5 milisegundos. Todo esse processo é discreto, descontínuo e, no entanto, percebemos o mundo externo de maneira unificada, como um continuum no tempo. Isto significa que as imagens se criam uma após a outra tão rápido que as percebemos tal como sucede com uma projeção cinematográfica. Ou seja: os estímulos procedentes de todos os sentidos se enlaçam, não em um lugar no cérebro, já que não existe um observador interno e nem uma tela para projeção, mas, sim, no tempo, que é determinado pela freqüência de escaneamento e pelas propriedades elétricas intrínsecas dos neurônios. O surpreendente é que este valor (12,5 ms.) corresponde ao "Quantum de Consciência" estimado a partir de estudos psicofísicos da via auditiva ${ }^{19}$, que é a via sensorial que possui o maior poder discriminatório entre dois estímulos aplicados em seqüência temporal, ou 
seja, os estímulos devem estar separados um do outro por um intervalo de tempo de $12,5 \mathrm{~ms}$. e não inferior, para que sejam percebidos como dois estímulos.

Outra tentativa de explicação vem de Gerald Edelman. Médico, foi o primeiro cientista a determinar a fórmula completa de um anticorpo. Seus estudos levaram ao entendimento de que a formação de anticorpos é presidida pelos mesmos princípios da seleção natural. Seus trabalhos no campo da imunologia renderamIhe o Prêmio Nobel de Medicina em 1972. Mais tarde, Edelman e seu grupo no Instituto de Neurociências da Universidade de Rockefeller passaram a estudar o sistema nervoso para ver se também este era um sistema selecional e se sua estrutura e modo de funcionamento poderia ser compreendida como envolvendo ou emergindo por um processo similar de seleção. Desses estudos, resultou uma teoria biológica da mente, baseada nos princípios da Seleção Natural de Darwin, denominada Darwinismo Neuronal ou Teoria da Seleção de Grupos Neuronais (TNGS, em inglês) 2,16. Essencialmente, Edelman desenvolveu seu modelo como um meio de explicar que nenhum programa de instruções genéticas pode dar conta de todas as possíveis respostas às situações ambientais que um animal está sujeito a encontrar e que, não obstante nossas experiências com o mundo externo serem unificadas, não existe uma localização anatômica onde a unificação é completada.

Sucintamente, a TNGS postula que desde o nascimento o cérebro é geneticamente equipado com uma quantidade excessiva de grupos neuronais, que o faz se desenvolver através de um mecanismo que se assemelha à Seleção Natural. Alguns grupos neuronais morrem; outros são fortalecidos e sobrevivem. Em algumas partes do cérebro, praticamente $70 \%$ dos neurônios morrem antes do cérebro alcançar a maturidade ${ }^{2}$.

De acordo com a TNGS, a unidade de seleção não é a célula nervosa, mas sim a coleção de células intensamente conectadas, chamadas Grupo Neuronal, que podem ter algumas dezenas ou centenas de milhares de células, e cujo desenvolvimento ocorre em duas etapas. A seleção desenvolvimental dá-se antes do nascimento. As instruções genéticas de cada organismo determinam o desenvolvimento neuronal sem, no entanto, especificar o destino exato para cada célula nervosa na migração que ocorre durante o desenvolvimento embriãofeto-bebê, sendo que existe uma quase infinita variação de caminhos pelos quais esses neurô- nios e sinapses podem tornar-se funcionalmente organizados em redes neurais. A segunda etapa é a seleção experiencial: sobrepondo-se ao período pós-natal inicial e continuando por toda a vida, a experiência esculpe os caminhos funcionais neurais a partir da disposição anatômica primitiva ${ }^{12}$. Os caminhos então utilizados durante a experiência são selecionados pelo fortalecimento das conexões sinápticas entre grupos neuronais ou pela criação de novas conexões. Aquelas conexões não utilizadas são enfraquecidas e degeneram.

O terceiro postulado é a reentrada, um processo através do qual sinais paralelos transitam reciprocamente entre os grupos de neurônios. A TNGS usa a reentrada como um mecanismo chave para explicar como ocorre o enlace (unificação de percepções e comportamento), a despeito do fato de não haver um processador central ou um detalhado conjunto de instruções coordenando áreas cerebrais funcionalmente separadas ${ }^{20}$. A sincronização da atividade neuronal possibilitada pela reentrada habilita rápidas alterações na atividade de grandes populações de grupos neuronais. Como resultado, neurônios desses grupos disparam ao mesmo tempo, correlacionando um grande número de circuitos dinâmicos no tempo e no espaço.

Segundo Edelman, este princípio de enlace, tornado possível pela reentrada, é repetido em muitos níveis da organização cerebral e joga um papel central nos mecanismos que levam à consciência.

\section{CONSCIÊNCIA E MEMÓRIA}

Para falarmos da relação das funções da consciência com a memória, inicialmente conceituaremos as memórias com as quais iremos trabalhar para fins deste texto.

\section{Sistemas de memória de longo prazo}

A Memória Declarativa (ou Explícita) é toda aquela memória que podemos lembrar, através de uma evocação. É a memória para fatos, eventos e conhecimentos. A localização no cérebro compreende principalmente hipocampo e córtex temporal medial. Divide-se em episódica (fatos e eventos aos quais assistimos ou participamos; portanto, é autobiográfica) e semântica (de conhecimento dos idiomas, conhecimentos adquiridos por meio de estudo e aprendizado, de índole geral, não autobiográfica). É em princípio acessível à consciência.

A Memória Procedural (ou Implícita) com- 
preende a memória de procedimentos, hábitos e habilidades, mas não apenas motores como antes se acreditava. Funções cognitivas complexas e subjetivas, como padrões morais, utilizadas no juízo de valor, podem fazer parte da memória implícita, e a sua existência só é depreendida através da observação do proceder do indivíduo. Esta tem no estriado uma estrutura chave. Compreende também a memória ligada à musculatura esquelética (localizada no cerebelo).O núcleo caudato inervado pela substância nigra é um circuito importante envolvido na memória implícita. É inconsciente ${ }^{21,22,23}$

\section{Anatomia da memória episódica}

As estruturas que são as mais importantes para a memória episódica são muito diferentes das que servem à memória procedural e semântica. A memória episódica envolve ativação consciente de padrões estocados de conectividade cortical (i.e., redes sinápticas facilitadas) representando eventos perceptuais prévios. Os diretórios de tais links entre os padrões corticais estocados e vários estados do SELF parecem ser codificados, acima de tudo, através do hipocampo.

É um problema de grande importância para o entendimento da memória episódica que a rede de estruturas que compreende o sistema límbico foi primeiro identificada não em conexão com as funções da memória, mas ao invés disto, em conexão com a emoção. Isto sublinha a importância do fato de que a memória episódica não é simplesmente estocada, mas, mais do que isto, vivenciada. A essência da memória episódica é que ela é CONSCIENTE, e a essência dos estados auto-gerados de consciência é que eles são intrinsecamente EMOCIONAIS. Este é o motivo pelo qual nós dizemos que a consciência é tanto o mensageiro como a mensagem da memória episódica: nós recobramos eventos de forma episódica para lembrar como é senti-los. ${ }^{23}$

\section{Memória episódica e consciência}

Memória episódica envolve a literal re-experiência de eventos passados - o trazer à tona a consciência de episódios experienciais prévios. Isto é o que a maioria de nós entende como memória propriamente dita. Quando dizemos "eu lembro...(algo)," nós estamos falando da memória episódica. O sistema de memória episódica "nos permite explicitamente rememorar incidentes pessoais que definem as nossas vidas de maneira única". A ênfase aqui reside nos fatos de que essas memórias são intrinsecamente subjetivas e que elas são intrinsecamente conscientes.

Por que deveriam as nossas memórias de eventos de vida pessoais necessariamente ser conscientes? Aqui reside um problema fundamental. Estas memórias são conscientes porque elas envolvem o reviver de momentos de experiências passadas. Sabemos que estes momentos de experiência são encontros momentâneos de estados do self com eventos ocorrentes no mundo externo - e nós sabemos que a consciência (ou consciência central) é tanto o mensageiro quanto a mensagem destes encontros. A memória episódica, então, constitui o tecido essencial do self autobiográfico. A consciência ampliada é assim denominada precisamente porque amplia a qualidade de consciência vivenciada no passado sobre os encontros self - objeto. Ela envolve o reviver de momentos passados ( ou "unidades" self-objeto passadas) de consciência central ${ }^{23}$.

Mas será que o conhecimento autobiográfico é necessariamente consciente? Os psicoterapeutas rotineiramente relatam que seus pacientes "recuperam" memórias de eventos vividos dos quais estes eram previamente não conscientes. Será que estas memórias não estavam previamente codificadas como episódios? Elas existiam previamente como crenças semânticas e hábitos procedurais? Se isto for verdade, todas as assim chamadas memórias recuperadas serão de fato memórias reconstruídas, no sentido de que elas serão feitas de material cru que não era, em si, "episódico". Por outro lado, parecerá plausível que um episódio pessoal possa deixar um traço neural (uma conexão self - mundo externo) que liga duas representações verídicas (um estado do self com eventos ocorrentes no mundo externo) e só se torna consciente uma vez que a ligação (como opondo-se às representações propriamente ditas) é ativada novamente. E mais, é questionável se um estado do self pode ser representado sem necessariamente ser reativado. Em outras palavras, os estados do self devem ser intrinsecamente conscientes (Não podemos dizer que lembramos sem simultaneamente sermos). O sentido de self parece ser necessariamente consciente (Eu estava lá, aquilo ocorreu comigo). Isto implica que, apesar dos eventos externos poderem ser codificados inconscientemente no cérebro (como semântico, perceptual, ou traços procedurais), o vivenciar episódico destes eventos aparentemente NÃO PODE. Experiências não são meros traços de estímulos 
passados. Experiências têm de ser vividas. É o revivenciar do evento como uma experiência (Eu lembro...) que necessariamente a torna consciente. E é o sentido do self (de estar aqui) que combina os traços dentro de uma experiência. É o self que liga nossas representações fragmentadas do mundo externo para unificar as experiências vividas. A ligação no encontro self-mundo externo é, em última análise, o próprio SELF.

Isto nós aparentemente redescobrimos de um ponto de vista neurocientífico, o fato óbvio de que aquilo que sentimos sobre nossas experiências é o que faz elas serem suscetíveis à repressão. Mesmo que façamos uma recordação perfeita do ponto de vista semântico, perceptual ou procedural, os múltiplos traços exteroceptivos de um evento têm de ser trazidos de volta a uma conexão existente com e por meio do SELF sensível, que vai sentir se o evento será conscientemente revivido (isto é, rememorado de forma episódica). Nada que impeça estas conexões pode banir a memória da consciência ampliada.

Tudo isto sugere que, quando os psicoterapeutas falam de memórias inconscientes de eventos pessoais, ao que eles estão se referindo realmente é a algo que as memórias estocadas dos eventos em questão seriam, como se eles pudessem ser re-experienciados. Memórias inconscientes dos eventos (memórias episódicas inconscientes) são memórias episódicas "como se". Elas não existem como experiências até que sejam reativadas pelo SELF corrente. Neste ínterim, elas somente existem sob forma de traços semânticos e procedurais (hábitos e crenças). ${ }^{23}$

\section{Memória procedural e o inconsciente}

Uma importante característica da memória procedural é que ela funciona implicitamente. $\mathrm{O}$ comportamento habitual é executado automaticamente (e portanto inconscientemente) quase que por definição. À medida que a memória procedural é tornada explícita, ela se transforma em algo mais, é traduzida para a forma semântica ou episódica. Por exemplo, é amplamente sabido que a prática de alguns esportes pode se desenvolver sem um correspondente conhecimento explícito de como a pessoa deve fazer para jogar. Jogadores experientes (tênis, p. ex.) descrevem seus momentos de auge quando, em uma situação de completa automaticidade na qual eles não pensam conscientemente em como executar o golpe e a raquete corpo, criam jogadas inesperadas.

Tipicamente, memórias procedurais vão estar associadas com memórias semânticas e memórias episódicas. Isto significa que a mesma experiência será codificada de diversas maneiras simultaneamente - como um set de episódios experimentais, como um set de fatos abstratos e como um set de respostas habituais. Esta é a manifestação da redundância da memória. Como resultado, é bastante possível que o comportamento de uma pessoa seja determinado por influências e eventos dos quais a pessoa é totalmente não consciente.

Isto é obviamente relevante para alguns fenômenos com os quais lidamos nas psicoterapias. Adiciona outra dimensão para o fenômeno da transferência e sua ligação em relação à memória perceptual. A transferência claramente se cerca de aspectos da memória procedural. Não se sabe ao certo em que extensão isto se aplica a outros fenômenos de interesse dos psicoterapeutas - tais como as memórias bodily, que alguns pacientes pós-traumáticos possuem. Além disto, alguns comportamentos emocionais (como reações de medo inconsciente a estímulos nociceptivos condicionados) certamente se parecem com memórias procedurais. Talvez a colaboração interdisciplinar futura entre psicoterapeutas e neurocientistas permita diferenciar mais precisamente os subsistemas de memórias "procedurais". ${ }^{23}$

\section{CONCLUSÃO}

A questão da consciência continua a representar um desafio ao nosso entendimento; porém, nos últimos 3 anos o terreno parece que se tornou menos obscuro. A proposta clara, embasada e receptiva para a inclusão dos achados de outros autores feita por Antônio Damá$\mathrm{sio}^{4}$, forneceu, ao nosso ver, uma linha mestra para os desenvolvimentos que estão por vir. Ao mesmo tempo, desprendeu-nos de concepções anteriores elusivas, como as de que a consciência era simplesmente o produto do cérebro todo em funcionamento, eximindo-se de buscar suas especificidades, o que Searle ${ }^{2}$ caracterizou como "resolver um problema através de negar a sua existência”, ou propostas dualistas, que situam a consciência como sempre "algo que está além”, dependente do funcionamento neural, mas não equivalente a este funcionamento mesmo, como criticaram Churchland ${ }^{14} \mathrm{e}$ Schwartz ${ }^{13}$, entre outros.

Este trabalho buscou familiarizar a quem ainda não tem maior contato com o tema com algumas idéias básicas e com alguns autores 
importantes dentro deste tópico. Dominar o tema é impossível, já que este nem consta de muitos livros texto recentes de neurociência, ou quando consta é, como no importante 'Principles of Neural Science' de Kandel, Schwarz e Jessel, de 2000, como um apêndice falando da futura neurociência do século XXI. Mas, mesmo assim, a bibliografia existente já é vasta e, talvez pela não-familiaridade que ainda temos com ela, complexa. Porém, desejamos que este trabalho sirva aos que o lerem, não como uma referência, pois temos suficiente consciência para não nutrir tal pretensão, mas como um estímulo para chamar a sua atenção para este tema tão fascinante, do mesmo modo que ocorreu para nós, coordenador e integrantes do grupo.

\section{REFERÊNCIAS BIBLIOGRÁFICAS}

1. Sutherland S. "The Macmillan Dictionary of Psychology", Macmillan; (1989) em De La Fuente R, Leefmans FJA Biologia de la Mente, México: Fondo de Cultura Económica; 1999.

2. Searle J. The Mystery of Consciousness, New York Review Book, New York, 1997. ("O Mistério da Consciência", Rio de Janeiro: Ed. Paz e Terra; 1998).

3. Agostinho S. "Confissões", São Paulo: Ed. Nova Cultural Ltda; 2000

4. Damásio A. The Feeling of What Happens, William Heinemann Ed., London, 1999.

5. Rolls ET. The Brain and Emotion, Oxford Univ. Press, Oxford, 1999.

6. Salzano FM. "Biologia, Cultura e Evolução", $2^{\text {a }}$ edição, Porto Alegre: Ed. da Universidade/UFRGS;1993.

7. Toynbee A. "A Humanidade e a Mãe Terra", Rio de Janeiro: Zahar Editores; 1982

8. Dennett D. "Consciousness Explained", Boston: Brown, 1991; em Leakey R, "A Origem da Espécie Humana", Rio de Janeiro, Ed. Rocco; 1997.

9. Leakey R. "A Origem da Espécie Humana", Rio de Janeiro: Ed. Rocco; 1997

10. Blanc M. (1994) Os Herdeiros de Darwin, editora Página Aberta, São Paulo.

11. Gould SJ. Ontogeny and Phylogeny, the Belknap Press of Harvard University Press, London, 1977.

12. Pally R. The Mind-Brain Relashionship, Karnac Books, London, 2000.

13. Schwartz JH. "Consciousness and the Neurobiology of the Twenty-First Century, in: Kandel, Schwartz \& Jessel Editors, Principles of Neural Science, $4^{\mathrm{a}}$ ed, McGraw-Hill, New York, 2000.

14. Churchland PM \& Churchland PS. On the Contrary: Critical Essays, Bradford Book, MIT Press, Cambridge, 1998.

15. Solms M. "What is Consciousness?", JAPA, 1997 ; 45, 3, 681-703

16. Edelman GM \& Tononi G. A Universe of Consciousness, Basic Books, New York, 2000

17. Gray CM \& Singer W. "Stimulus-specific Neuronal Oscilations in Orientation Columns of Cat Visual Cortex". Proc.Natl.Acad. Sci. USA.86:1698-1702:1989. In: La Fuente e Leefmans, Biologia de la Mente, Fondo de
Cultura, México, 1999

18. Llinás R e Paré D. Of Dreaming and Wakefulness, Neuroscience. 44:521-535; 1991 IN De La Fuente R, Leefmans FJA, Biologia de la Mente, Mexico: Fondo de Cultura Económica; 1999

19. Kristofferson, A.B. "Quantal and Deterministic Timing in Human Duration and Discrimination". Ann. NY Acad. Sci. 423:3-15, 1984, in: De La Fuente R, Leefmans FJA, Biologia de la Mente, México: Fondo de Cultura Económica; 1999

20. EdelmanG. Bright Air, Brillant Fire, London: Penguin Books;1992

21. Kandel, Schwartz \& Jessel eds. Principles of Neural Science, 4를 ed., McGraw-Hill, New York, 2000.

22. Bear, Connors \& Paradiso eds. Neurociências, $2^{\underline{a}}$ ed., Artmed Ed., Porto Alegre, 2002.

23. Solms M, Turnbull O. The Brain and the Inner World, Karnac Books, London, 2002.

\section{RESUMO}

Após um século da ênfase nos processos mentais inconscientes dada por Freud, estes se tornaram largamente aceitos, e, nos últimos anos, na verdade tem se verificado que o maior mistério reside na natureza da consciência. A distinção entre a consciência no sentido de coma/vigília, no sentido de consciência moral e no sentido da sensação de existir e estar vivenciando algo, encontrou respaldo nos avanços da neurociência. Esta última acepção, o "sentimento do que acontece" nas palavras de Damásio, presente durante o sonhar e ausente em certos estados de vigília como nas crises de ausência, é a propriedade de certos processos mentais que mais tem sido alvo de estudo. Evidências recentes sugerem que tanto a sensação de continuidade da consciência quanto a impressão de que ela preceda a tomada de decisão seriam ilusórias. Também a antiga crença de que a consciência fosse uma função dependente de um funcionamento cortical global tem sido questionada. A evolução da consciência a partir dos mecanismos de homeostase, como um feedback sofisticado dos processos mentais que permite a detecção de erros nas predições realizadas pelo cérebro sobre o self e o ambiente, com a possibilidade de correções em partes do processo mental sem a necessidade de descartá-lo por inteiro, são exemplos das modernas compreensões sobre este tema, e que têm importantes implicações para a clínica psicoterápica.

Neste trabalho, os autores revisam algumas das principais teorias recentes sobre a consciência, sua natureza, funções, aspectos evolucionistas, relação com a linguagem, com os sistemas de memória e com a questão da integração dos diferentes inputs e registros mnêmicos numa cena unificada do self interagindo com o ambiente, salientando que, embora já tenhamos alguns desenvolvimentos muito interessantes, a compreensão do tema ainda está nos seus primórdios.

Descritores: consciência, evolução, neotenia, integração, memória, neuropsicanálise. 


\section{ABSTRACT}

A century after Freud's emphasis on unconscious mental processes they have become largely accepted. In the last years we have come to recognize that the greatest mystery lies on the nature of consciousness. The distinction among wakefulness, moral conscience and consciousness in the sense of being experiencing something have found support on the latest neuroscientific findings. In this last sense of 'the feeling of what happens', as Antônio Damásio wrote, consciousness is present in dreaming and may be absent in certain fully awake states like absence seizures, and that's the phenomenon which has been receiving growing attention.

Latest evidences point to the fact that the sensation of continuity as much as the impression that consciousness preceedes decision making are illusory. The old belief that consciousness were a global cortical function is also being questioned. Evolution of consciousness by differentiation of basic homeostatic mechanisms, as a sort of sophisticated feedback system for mental processes that allows for mistake detection on brain's predictions about self and environment, with the possibility of making corrections in parts of the mental process without having to discard it as a whole, are examples of modern comprehensions on this issue that bear implications to psychotherapeutic practice.

In this article the authors review some of the main recent theories on consciousness, its nature, functions, evolutionary aspects, its relation to language, memory systems and to the 'binding problem' of reconciling various inputs and mnemic traits within a unified scene of the self interacting with the environment, emphasizing that, although there are already exciting developments, understanding of consciousness is still in its beginnings.

Keywords: consciousness, evolution, neoteny, integration, memory, neuro-psychoanalysis

Title: Consciousness: some current conceptions on its nature, function and neuroanatomic basis

Endereço para correspondência:

Maurício Marx e Silva

Rua Mostardeiro, 333, conj. 514

90430-001 - Porto Alegre - RS - Brasil

E-mail:maurimarx@terra.com.br

Copyright (c) Revista de Psiquiatria do Rio Grande do Sul - SPRS 